\title{
Endoscopic application of clipping, over-the-scope clip (OTSC) and stenting for a fistula and anastomotic leakage of upper gastro- intestinal tract
}

Hiroshi Makino $^{1 *}$, Satoshi Nomura ${ }^{1}$, Hiroshi Maruyama ${ }^{1}$, Tadashi Yokoyama ${ }^{1}$, Atsushi Hirakata ${ }^{1}$, Yuta Kikuchi ${ }^{1}$, Masafumi Yoshioka ${ }^{1}$, Takuma Iwai ${ }^{1}$, Tsutomu Nomura ${ }^{2}$ and Hiroshi Yoshida ${ }^{2}$

${ }^{1}$ Department of Surgery, Nippon Medical School, Tama Nagayama Hospital, Japan

${ }^{2}$ Department of Gastro Intestinal and Hepato-biliary-pancreatic Surgery, Nippon Medical School, Japan

\begin{abstract}
After esophagectomy and total gastrectomy, anastomotic leakage is a serious complication associated with a high mortality. Complications such as abscesses, sepsis and malnutrition may occur. In cases of anastomotic leakage after esophagectomy and gastrectomy, occurrence of an esophago-respiratory fistula or pancreatic fistula can be a very dangerous, even fatal complication.

Various endoscopic techniques have been recently developed to treat leakage and fistula using minimally invasive approaches. Treatment methods including techniques such as fibrin glue injection, use of clips or self-expandable stents which are more conservative than surgery have become available. We report successful endoscopic clipping and application of fibrin glue, which is more conservative than surgery, for an esophago-mediastinal fistula. In addition to reporting endoscopic application of transnasal tube, over-the-scope clip (OTSC) and stenting, we also performed clipping for difficult cases with leakage or fistula. In this paper, indications of these endoscopic therapeutic methods are described for each case. With a broad range of conservative and endoscopic therapeutic methods available, encouraging progress has been made with regards to a shorter closure time of leakage and less risk of severe systemic complications.
\end{abstract}

\section{Introduction}

Anastomotic leakage after esophagectomy and gastrectomy can result in abscess, subsequent sepsis and a longer hospital stay. Anastomotic fistula and mediastinitis are potentially major complications of post-esophagectomy and represent main determinants in postoperative morbidity and mortality $[1,2]$. This condition is very serious, predisposing a patient to life-threatening pneumonia. Several studies have reported anastomotic leakage incidence of approximately $5 \%$ after gastrectomy, and an incidence of approx. $10 \%$ after esophagectomy.

Generally accepted aims of the immediate treatment are sepsis source control, sufficient drainage of the leakage and perianastomotic drainage, parenteral nutrition, naso-gastric decompression and broad spectrum antibiotics. However, how to achieve leakage control still remains controversial. Possible treatment options must achieve drainage of the septic focus in the mediastinum and abdomen, and close the esophageal and gastric wall defect or the dehiscent circular staple line of the anastomosis.

Surgical treatment is sometimes unavoidable in cases of esophagorespiratory fistula or severe infection. High mortality rates of 33-64 $\%$ following revisional surgery for anastomotic leakage after upper gastrointestinal reconstruction have been reported [3].

There are various advanced endoscopic therapies for esophageal anastomotic leakage. Over-the-Scope Clip (OTSC) can hold and strongly compress tissue and close the leakage [4]. OTSC has been used to seal various chronic leakages [5]. Alternative endoscopic techniques include endoscopic vacuum assisted closure, and endoscopic insertion alpha cyanoacrylate [6]. Endoscopic implantation of covered stents is an alternative option to treat larger lesions [7]. We would like to report cases of endoscopic clipping used to close mediastinal fistula after esophagectomy [8].

In this paper, we reported various endoscopic treatments and present the treatment flow chart for anastomotic leakage after esophagectomy.

\section{Patients and methods}

Thirteen patients received the following endoscopic methods after esophagectomy or gasterectomy since 2005.

\section{Endoscopic management by clipping}

Previously we reported successful treatment for anastomotic leakage after esophagectomy. From the third treatment of clipping, endoscopic closure by clipping and fibrin glue was performed.

(1) The metallic clip attachment device with a loaded clip (OLYMPUS, Tokyo, Japan) can be passed through the forceps channel of a standard endoscope.

*Correspondence to: Hiroshi Makino, Department of Surgery, Tama Nagayama Hospital, Nippon Medical School, 1-7-1 Nagayama, Tama-City, Tokyo, Japan- 206-8512, Tel: +81-42-371-2111, Fax +81-42-372-7384, E-mail: himiyumo@nms.ac.jp

Key words: fistula, leakage, endoscopy

Received: May 13, 2019; Accepted: May 27, 2019; Published: May 30, 2019 
(2) Prongs are opened by pulling on the handle of the attachment device.

(3) By manipulating the tip of the endoscope, the clip can be positioned to hold the tissue flanks of the leakage after suction to reduce the size of the fistula.

\section{Endoscopic Over-The-Scope Clip (OTSC) placement}

The Over-The-Scope Clip (OTSC) system (Ovesco Endoscopy AG, Tubingen, Germany) was originally developed for hemostasis of non-variceal bleeding. This system can effectively close large defects in the gastrointestinal wall as a result of gastric and colonic perforations after endoscopic mucosal resection (EMR) or endoscopic submucosal dissection (ESD). This system was applied to 2 (two) cases after esophagectomy.

(1) Endoscopic deployment for fistula closure by approximating the margin of the fistula opening with a single clip device.

(2) Position the endoscopic cap in the center of the fistula opening, apply firm suction through the endoscopic channel to suction the surrounding tissues into the endoscopic cap attachment.

(3) Deploy the clipping device by turning the firing wheel attached to the endoscope handle.

\section{Endoscopic stent insertion}

Endoscopic stent insertion (EST) is easy and reliable, and performed in early stage cases. EST is often the first technique applied for fistula after esophagectomy.

(1) To close an anastomotic leak, a self-expandable, covered metal stent (Ultraflex ${ }^{\mathrm{ns}}$, Boston Scientific, Natick, MA, US or Flexella- $\mathrm{J}^{\mathrm{m}}$, PIOLAX, Kanagawa, Japan) are used.

(2) After confirmation by X-ray contrast, the exact position of the leak is marked on the patient's skin and stent placement is performed by interventional endoscopy.

(3) Correct placement of the stent and successful closure of the leak are always controlled by endoscopy as well as by contrast medium ingestion.

\section{Thoracic drainage inserted through trans-nasal route}

First a guidewire is inserted via the working channel of the endoscopy and the trans-nasal drainage tube is introduced through the guidewire at the site of the intrathoracic esophago-gastric anastomotic leak under endoscopic observation.

Continuous negative pressure of $5-10 \mathrm{mmHg}$ is applied using a vacuum pump. For cases of fistula close to the trachea or a major vessel, only trans-nasal drainage is performed.

\section{Results}

We successfully closed fistula and anastomotic leakage in all cases by endoscopic procedures.

\section{Endoscopic stent insertion}

A self-expandable partially covered metallic stent (Ultraflex ${ }^{\mathrm{mm}}$, Boston Scientific, Natick, MA, US) to seal the fistula was inserted on post operation day (POD) 79. The fistula was corrected and the patient could eat. However, one month after insertion, migration and abrasion of the stent was detected (Figure 1).
Another case showed major leakage after esophagectomy and cervical anastomosis. A removable self-expandable covered metallic stent (Flexella- $\mathrm{J}^{\mathrm{Tw}}$, PIOLAX, Kanagawa, Japan) was inserted on POD 15. To avoid migration gastrostomy anchor (smart anchor ${ }^{\mathrm{r}}$, TOP, Tokyo, Japan) was inserted into metallic stent. The stent was removed on POD 77 and anastomotic leakage is successfully closed (Figure 2).

\section{Endoscopic management using clipping}

Three cases with anastomotic leakage after esophagectomy and total gastrectomy were successfully treated and the fistula was closed (Figures 3,4). We previously reported a case of anastomotic fistula after esophagectomy [8]. In one case, a nasal drainage tube (ENBD tube) was first inserted after total gastrectomy on the POD 7 and then clipped on POD 14. Endoscopic closure of the fistula was achieved using regular or long clips.

\section{Endoscopic Over-The-Scope Clip (OTSC) placement}

On POD 12 after esophagectomy, fistula in the case was detected and closed by the OTSC system (Figure 5). In another case, we detected
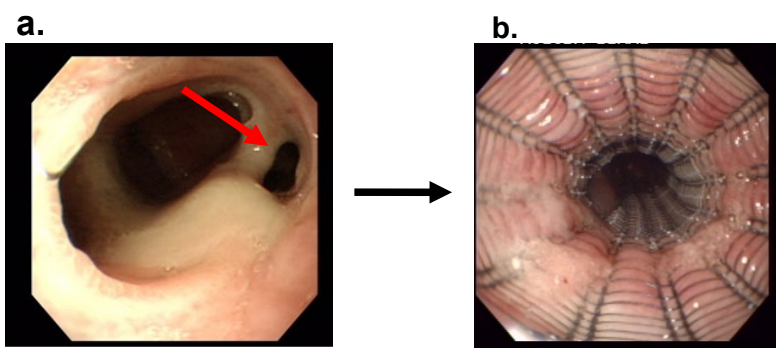

Figure 1: Closure of an anastomotic leakage after esophagectomy by self expandable covered metallic stent

a. As shown by endoscopy, the fistula after esophagectomy (arrow) failed to close on POD 79

b. The fistula was covered by the self expandable covered metallic stent and closed
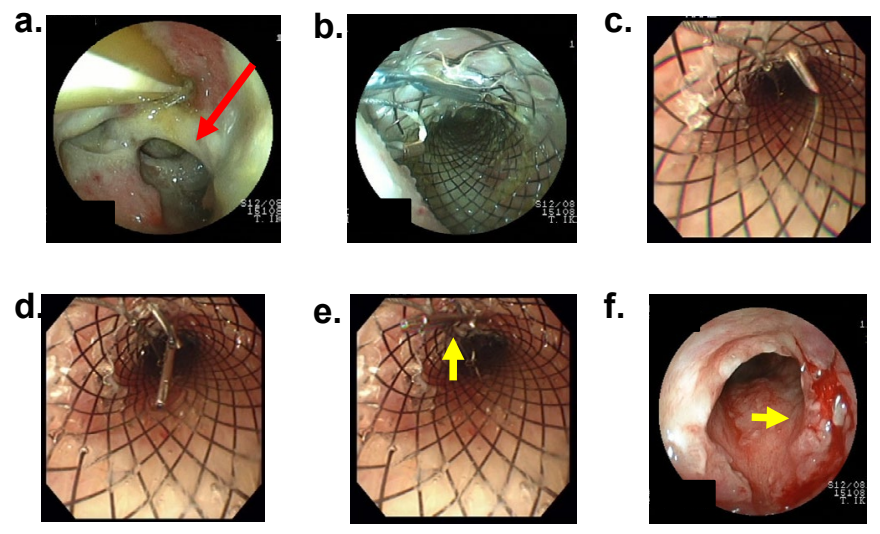

Figure 2: Closure of an anastomotic leakage after esophagectomy by removable self expandable covered metallic stent

a. Trans-nasal tube was inserted into gastric conduit. Major anastomotic leakage (red arrow) was observed by endoscopy on POD 4

b. The self expandable covered metallic stent was inserted into the gastric conduit through the esophagus on POD 15

c. The needle including the gastrostomy anchor (smart anchor TM, TOP, Tokyo, Japan) was inserted into covered stent

d. The smart anchor ${ }^{\mathrm{TM}}$ was released in the covered stent

e. The covered stent was fixed on the neck wall by smart anchor TM (yellow arrow) to avoid migration

f. Closure of the fistula (yellow arrow) was observed on POD 77 after removing stent by endoscopy 
anastomotic leakage on POD 5 and attempted closure by the OTSC system with a grasper, but the OTSC clip cut through both the tissue and grasper and closure was unsuccessful (Figure 6). But trans-nasal

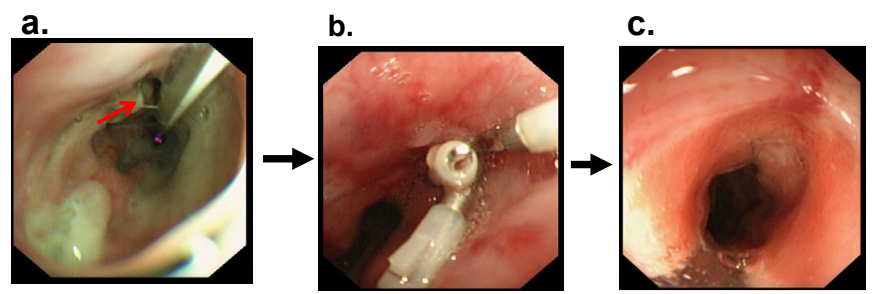

Figure 3: Closure of an anastomotic leakage after esophagectomy by clipping a. A fistula after esophagectomy was observed by endoscopy

b. Three clips were used to close the fistula with fibrin glue

c. Approximately five months (POD 154) after the operation, the patient shows no signs of recurrence of tumor or fistula

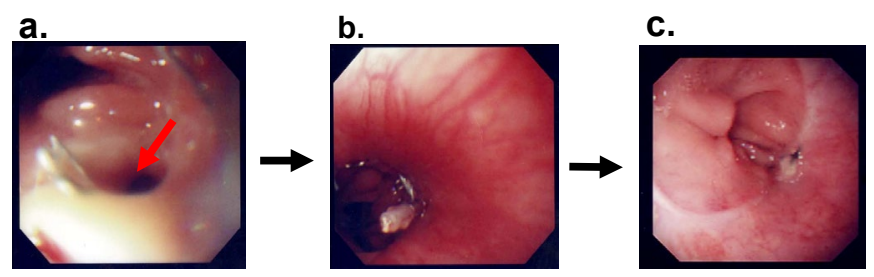

Figure 4: Closure of an anastomotic leakage after total gastrectomy by clipping a. Anastomotic leakage was observed after total gastrectomy on POD 7.

b. The fistula was clipped on POD 14

c. Endoscopic closure of the fistula was shown

a.

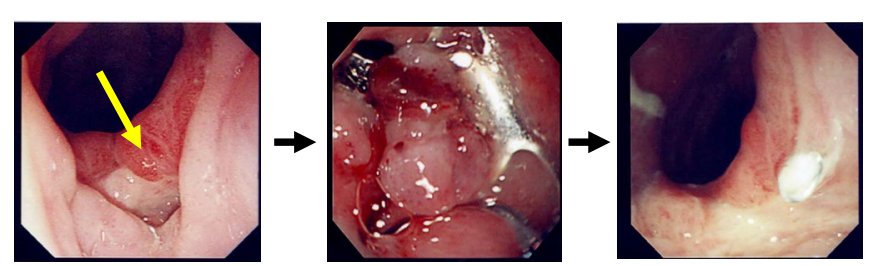

Figure 5: Closure of fistula by OTSC system

a. On POD 12 after esophagectomy, a fistula was discovered

b. The fistula was closed by the OTSC system

c. Follow up endoscopy showed clear anastomosis a.

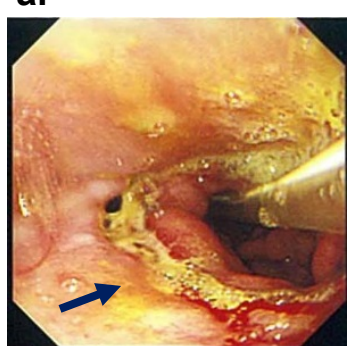

b.

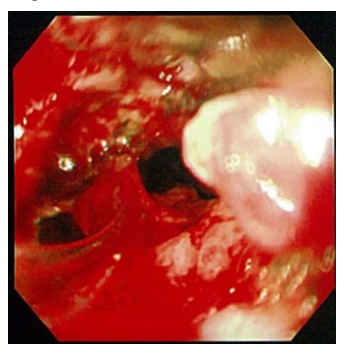

Figure 6: OTSC closing failure

a. In another case, leakage after esophagectomy was detected POD 5

b. Closure using the OTSC system with grasper was attempted, but failed tube was placed into a leak cavity by endoscopy and removed after confirming to reduce the size of the defect.

\section{Discussion}

Despite this favorable trend, anastomotic leakage after esophagectomy or total gastrectomy remains an important determinant of morbidity. Incidence of anastomotic leakage after esophagectomy is reported to be between $2.3 \%$ and $15.3 \%$ [911], and anastomotic leakage accounts for approximately $40 \%$ of all postoperative deaths [12]. In contrast, mortality after total gastrectomy is approximately $0 \%$ [13].

Cases of suspected leakage of intrathoracic anastomosis were identified by endoscopy and CT of the chest and abdomen. All anastomotic leaks were endoscopically verified.

Additional stent placement in conservative management of esophageal anastomotic leakage after esophagectomy has excellent advantages of immediate leak occlusion, such as allowing for early oral feeding and avoidance of further contamination of the mediastinum, and also results in a shorter intensive care unit and hospital stay.

Endoscopic implantation of covered stents is an alternative option to treat larger lesions. This technique is easily available and effective, and is associated with a low morbidity [7,13-16]. The most common complication of stent therapy is stent migration, occurring in $49 \%$ of cases of esophagogastrostomy, $61 \%$ of cases of esophagojejunostomy, and $100 \%$ of cases of esophagocolonostomy, but the rate of stent dislocation for the Niti-S stent was 17\% [13]. Early, intermediate, and late stent migrations were experienced in $21 \%, 24 \%$, and $15 \%$ of cases respectively [13]. Migration was predicted because stenosis at the anastomotic site was not observed. Moreover the anastomotic site was located near the neck and odynophagia was assumed to occur when the upper level of the stent was located over the top of the sternum level. We firstly reported to avoid covered stent migration using gastrostomy anchor after esophagectomy with cervical anastomosis.

There are still no general recommendations and guidelines on how to use stents to treat intestinal leakages.

Surgical intervention is indicated for mediastinitis, widespread graft necrosis and abscesses due to leakage [2]. There are reports of attempts to directly repair these conditions by suturing and covering with omentum or muscle flap. In cases where the fistula leads to the respiratory tract, such operations are considered be necessary due to the risk of repetitive pneumonia leading to poor physical condition [13].

Mortality of patients receiving a second operation is high (40\%) [7]. Resection should be considered in cases of severely compromised or necrotic graft. Surgical treatment of esophageal anastomotic leaks, however, has been linked to subsequent death $[1-3,7,17]$.

Ojima reported successful treatment of fistula with an injection of alpha-cyano acrylate monomer [6]. Endoscopic filling of the fistula with fibrin glue is also reported as an effective treatment by some investigators $[8,18,19]$. Thrombin and fibrinogen provide a surgical seal, and adhesion strength of the clot is directly correlated with the concentration of fibrinogen in the fibrin sealant. We previously reported that this technique is insufficient for fistula closure and subsequently added clipping [8]. 
The use of metallic clips for hemostasis and closure of a perforation due to various causes has been reported. Endoscopic closure by clipping was found to be effective for idiopathic or iatrogenic perforations $[8,20]$.

Rodella et al. reported that endoscopic clipping to close an anastomotic leakage after a gastrectomy was effective and required only a short hospital stay [21]. Endoscopic clipping is recommended by Rodella to treat leakages less than $2 \mathrm{~cm}$ in diameter; the diameter of the fistula in our case was also less than $2 \mathrm{~cm}$. Applying suction with the endoscope was helpful when attempting to close the fistula by clipping, since size of the fistula could be reduced [8]. Application of endoscopic clipping as soon as possible after operation or in a period once inflammation and infection have subsided was considered. Application of endoscopic clipping and fibrin glue is an attractive treatment, but fibrin-glue injections or clips may only seal small esophageal leaks [18-22]. As noted, all these techniques are only feasible and practical for small leaks and proper treatment for larger dehiscences remains unresolved.

The OTSC system is also available. The OTSC system has been shown to be suitable for closing acute small gastrointestinal perforations, and its use in treatment for chronic leakage has recently been reported $[5,24,25]$. Mercky reported achieving successful OTSC placement in 30 out of 34 attempts, with an overall success rate of $71.4 \%$ and 16 patients (53\%) recovered with primary efficacy [5].

Standard clips are too small and lack sufficient strength for a reliable suture compared to OTSC, which allow closure of gaps $<30$ $\mathrm{mm}$ [5]. Biological fibrin glue can be useful for leak closure, but is mainly associated with other treatment modalities. The best results are observed for fistulas $<5 \mathrm{~mm}$ [5]. New clipping devices such as OTSC, are recently being used as a good alternatives to standard clips, since a single clip allows for steady closure of perforations $\leq 2.5 \mathrm{~cm}[5]$.
Based on our previous experience with nasogastric tubes through fistula sites into the thoracic cavity [23] and according to literature review, we designed the thoracic drainage tube which can be inserted through the transnasal route to clear infected secretions, shrinking the para-anastomotic cavity and eventually allowing closure of the defect.

Endoscopic Vacuum-Assisted Closure (E-VAC) therapy of anastomotic leakages was developed to overcome current limitations associated with intermittent endoscopic treatment and conventional drainage therapy [27-29]. This treatment is effective and non-invasive. Less infection in the fistula is observed in cases of vacuum drainage using a nasal gastric tube with sponge. Timing of clipping and filling with fibrin glue should coincide with the lowest rate of infection.

On the other hand, transoral endoscopic placement of a sponge into a leak by E-VAC is technically demanding and the sponge must match the size of the defect. Hence, there is still room for improvement in this method. Moreover, patients must undergo repeated gastroscopy for sponge exchange.

We adopted a similar method that does not use a sponge for four (4) cases and could successfully close the fistula [23]. One disadvantage of this method is the need for a long hospital stay.

As shown in Figure 7, we consider indications of endoscopic methods for anastomotic leakage or fistula according to the size of them and firstly show the indication. In the case of a small leakage or fistula after drainage, clipping (less than $2 \mathrm{~cm}$ in diameter) and filling with fibrin glue (less than $5 \mathrm{~mm}$ in diameter) should be adopted in order to close the leakage and fistula. The OTSC system allows closure of gaps $<30 \mathrm{~mm}$ of anastomotic leakage or fistula. A large anastomotic leakage or fistula should be treated by the transnasal intra-thoracic drainage without other peri-anastomotic drainage or covered with a self-expandable metallic stent with other peri-anastomotic drainage.

\section{Leakage or fistula of anastomosis}

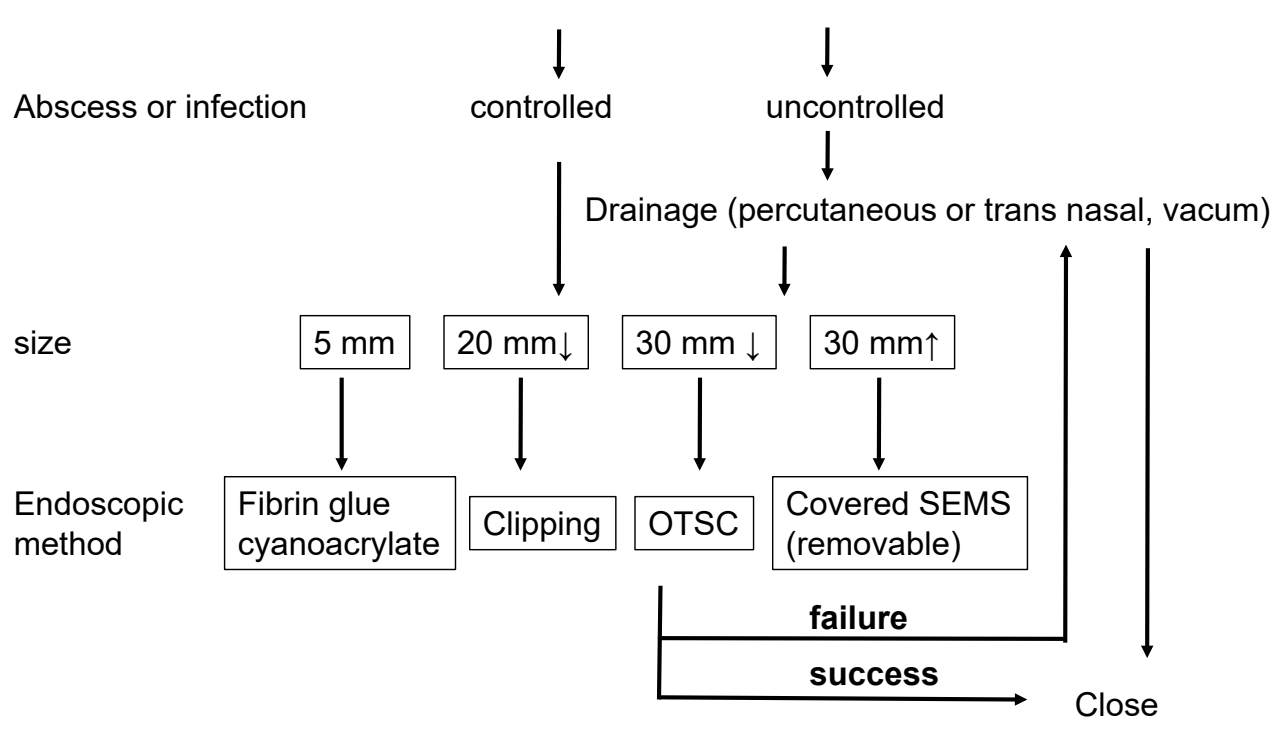

Figure 7: Diagram showing the management flow of patients with leakage or fistula of anastomosis 


\section{Conclusions}

These endoscopic treatments are simple and safe methods for the management of postoperative leakages and fistulas of the gastrointestinal tract. The most suitable method, stent therapy, endoscopic drainage therapy, clip and OTSC application should be selected for each patient experiencing postoperative leakage.

\section{Compliance with ethical standards}

Our work conforms to the guidelines set forth in the Helsinki Declaration of 1975, as revised in 2000 (5), concerning Human and Animal Rights, and the authors followed the policy of the Committee on Publication Ethics guidelines.

\section{Conflict of interest}

There are no financial or other relationships that could lead to a conflict of interest.

\section{Footnote}

Ethical statement: The study was approved by Institutional Ethics Board of Nippon Medical School, Tama Nagayama Hospital (approval ID number is 525), and written informed consent was obtained from all patients.

\section{References}

1. Alanezi K, Urschel JD (2004) Mortality secondary to esophageal anastomotic leak. Ann Thorac Cardiovasc Surg 10: 71-75. [Crossref]

2. Lang H, Piso P, Stukenborg C, Raab R, Jahne J (2000) Management and results of proximal anastomotic leaks in a series of 1,114 total gastrectomies for gastric carcinoma. Eur J Surg Oncol 26: 168-171. [Crossref]

3. Turkyilmaz A, Eroglu A, Aydin Y, Tekinbas C, Muharrem Erol, et al. (2009) The management of esophagogastric anastomotic leak after esophagectomy for esophageal carcinoma. Dis Esophagus 22: 119-126. [Crossref]

4. Galizia G, Napolitano V, Castellano P, Pinto M, Zamboli A, et al. (2012) The Over-TheScope-Clip (OTSC) System is Effective in the Treatment of Chronic Esophagojejunal Anastomotic Leakage. J Gastrointest Surg 16: 1585-1589. [Crossref]

5. Mercky P, Gonzalez JM, Bonin EA, Emungania O, Brunet J, et al. (2014) Usefulness of over-the-scope clipping system for closing digestive fistulas. Dig Endosc 27: 18-24. [Crossref]

6. Ojima T, Nakamori M, Nakamura M, Katsuda M, Iida T, et al. (2014) Successful treatment of esophageal fistulas with endoscopic injection of alpha-cyanoacrylate monomer. Endoscopy 46: E62-E63. [Crossref]

7. Schweigert M, Solymosi N, Dubecz A, Stadlhuber RJ, Muschweck H, et al. (2013) Endoscopic stent insertion for anastomotic leakage following oesophagectomy. Ann $R$ Coll Surg Engl 95: 43-47. [Crossref]

8. Makino H, Miyashita M, Nomura T, Hagiwara N, Takahashi K, et al. (2011) Successful endoscopic clipping and application of fibrin glue for an esophago-mediastinal fistula after an esophagectomy. Esophagus 8: 113-117.

9. Page RD, Shackcloth MJ, Russell GN, Pennefather SH (2005) Surgical treatment of anastomotic leaks after oesophagectomy. Eur J Cardiothorac Surg 27: 337-343. [Crossref]
10. Liu JF, Wang QZ, Ping YM, Zhang YD (2008) Complications after esophagectomy for cancer: 53-year experience with 20,796 patients. World J Surg 32: 395-400. [Crossref]

11. van Heijl M, van Wijngaarden AK, Lagarde SM , Busch OR, van Lanschot JJ, et al. (2010) Intrathoracic manifestations of cervical anastomotic leaks after transhiatal and transthoracic oesophagectomy. Br J Surg 97: 726-731. [Crossref]

12. Umemura A, Koeda K, Sasaki A, Fujiwara H, Kimura Y, et al. (2015) Totally laparoscopic total gastrectomy for gastric cancer: Literature review and comparison of the procedure of esophagojejunostomy. Asian J Surg 38: 102-112. [Crossref]

13. Feith M, Gillen S, Schuster T, Theisen J, Friess H, et al. (2011) Healing Occurs in Most Patients That Receive Endoscopic Stents for Anastomotic Leakage; Dislocation Remains a Problem. Clin Gastroenterol Hepatol9: 202-210. [Crossref]

14. Hoeppner J, Kulemann B, Seifert G, Marjanovic G, Fischer A, et al. (2014) Covered self-expanding stent treatment for anastomotic leakage: outcomes in esophagogastric and esophagojejunal anastomoses. Surg Endosc 28: 1703-1717. [Crossref]

15. Schweigert M, Solymosi N, Dubecz A, González MP, Stein HJ, et al. (2014) One decade of experience with endoscopic stenting for intrathoracic anastomotic leakage after esophagectomy: brilliant breakthrough or flash in the pan? Am Surg 80: 736-745. [Crossref]

16. Plum PS, Herbold Till, Berlth1 F, Christ H, Alakus H, et al. (2019) Outcome of SelfExpanding Metal Stents in the Treatment of Anastomotic Leaks After Ivor Lewis Esophagectomy. World J Surg 43: 862-869. [Crossref]

17. Salo JA, Isolauri JO, Heikkila LJ, Markkula HT, Heikkinen LO, et al.(1993) Management of delayed esophageal perforation with mediastinal sepsis. Esophagectomy or primary repair? J Thorac Cardiovasc Surg 106: 1088-1091. [Crossref]

18. Groitl H, Scheele J (1987) Initial experience with the endoscopic application of fibrin tissue adhesive in the upper gastrointestinal tract. Surg Endosc 1: 93-97. [Crossref]

19. Spotnitz WD (2001) Commercial fibrin sealants in surgical care. Am J Surg 182: 8S-14S. [Crossref]

20. Grupka MJ, Benson J (2008) Endoscopic clipping. J Dig Dis 9: 72-78. [Crossref]

21. Rodella L, Laterza E, De Manzoni G, Kind R, Lombardo F, et al. (1998) Endoscopic clipping of anastomotic leakages in esophagogastric surgery. Endoscopy 30: 453-456. [Crossref]

22. Lee JY, Ryu KW, Cho SJ, Kim CG, Choi IJ, et al. (2009) Endoscopic Clipping of Duodenal Stump Leakage After Billroth II. Gastrectomy in Gastric Cancer Patient. $J$ Surg Oncol 100: 80-81. [Crossref]

23. Makino H, Yoshida H, Uchida E (2012) Endoscopic Clipping and Application of Fibrin glue for an Esophago-Mediastinal Fistula. Corrent Concepts in General Thoracic Surgery: 263-278.

24. Baron TH, Louis M, Song WK, Ross A, Tokar JL, et al. (2012) Use of an over-thescope clipping device: multicenter retrospective results of the first U.S. experience. Gastrointest Endosc 76: 202-208 [Crossref].

25. Mennigen R, Colombo-Benkmann M, Senninger N, Laukoetter M (2013) Endoscopic Closure of Postoperative Gastrointestinal Leakages and Fistulas with the Over-theScope Clip (OTSC). J Gastrointest Surg 17: 1058-1065. [Crossref]

26. Wedemeyer J, Schneider A, Manns MP, Jackobs S (2008) Endoscopic vacuum-assisted closure of upper intestinal anastomotic leaks. Gastrointest Endosc 67: 708-711. [Crossref]

27. Weidenhagen R, Hartl WH, Gruetzner KU, Eichhorn ME, Spelsberg F, et al. (2010) Anastomotic leakage after esophageal resection: new treatment options by endoluminal vacuum therapy. Ann Thorac Surg 90: 1674-1681. [Crossref]

28. Schniewind B, Schafmayer C, Voehrs G, Egberts J, von Schoenfels W, et al. (2013) Endoscopic endoluminal vacuum therapy is superior to other regimens in managing anastomotic leakage after esophagectomy : a comparative retrospective study. Surg Endosc 27: 3883-3890. [Crossref]

Copyright: (C2019 Makino H. This is an open-access article distributed under the terms of the Creative Commons Attribution License, which permits unrestricted use, distribution, and reproduction in any medium, provided the original author and source are credited. 